\title{
Ergonomics Design Research of an Office Desks and Chairs Based on CAD
}

\author{
L.A. Pan \& Q.L. Du \\ College of Mechanical and Vehicle Engineering Changchun University, Changchun, China
}

Y.Q. Wu

Naval Aeronautical Engineering Institute, Qingdao, China

\begin{abstract}
Office leisure is the common pursuit of the enterprise, government, leadership and staff. The relaxed, happy, free and comfortable life is people always wish, also is inevitable to era development and social progress. So, according to the demand, indoor and outdoor dual-use multi-function folding leisure office furniture has been designed in the paper. First of all, through a large number of research and decisions, the structure of the product portfolio has been determined. In order to be convenient and quick, the characteristics of the furniture on the market have been collected and analyzed, especially the table, chairs and a bed. According to ergonomics, the parameters of the outdoor leisure office desks and chairs have been determined. The rhino software has been used to establish the combination of desk and chair to make the products comply with ergonomics, human psychology and aesthetic principles of the product.
\end{abstract}

KEYWORD: Office desks and chairs; CAD; Ergonomics; 3D Max

\section{GENERAL INSTRUCTIONS}

Office leisure is the common pursuit of the enterprise, government, leadership and staff. The relaxed, happy, free and comfortable life is people always wish, also is inevitable to era development and social progress. Leisure office is one of the diversified economies under the form of office means. Socialist harmonious society today, the Chinese government introduced a series of entertainment policy, our country's leisure economic development is very good, very soon. At the same time, with the improvement of people's living standard and the speed of new product development gradually speeding up, the product life cycle is getting shorter. With the rapid development of construction industry and people's housing conditions continue to improve, furniture products also accelerated the pace of upgrading, and the elimination rate increased significantly. The rich western countries want to throw away millions of desk, chair, table, ambry, mattress and etc. The office furniture products have been eliminated, not because of scrap, and in most cases because the product does not adapt to the request of the office conditions.[1]

So in this paper, indoor and outdoor dual-use multi-function folding leisure office furniture has been introduced. It brought together such as desk, office chair, computer desk, leisure bed features, is a novel structure, complete function, easy to carry light.

\section{THE DETERMINATION OF DESIGN SCHEME}

Along with the development of the market, transfer of consumers aesthetic habit, as well as the deepening of the concept of ergonomics, the timely transformation of the desk on the function and appearance is the trend of The Times. At the same time it also will provide us with a large space for development. From the point of desk in recent years the market situation, more and more manufacturers especially more professional manufacturer have fully realized the importance of differentiation on product function. According to the current situation, in this paper a multi-functional leisure folding desk has been designed. It has the features following folded, desk, office chair, outdoor leisure bed, computer desk, easy to carry, outdoor and Indoor desk, and etc.[2]

In this paper, design of outdoor leisure furniture has been shown in figure 1, 2, 3 .

The inspiration of the design was from small universal machine tools. Because our life is diverse, at the same time intervals, a variety of tools can been use, but it is not reality to carry a variety of tools. In order to be able to well meet the purpose of outdoor 
leisure travel office, the new outdoor leisure furniture has been designed to solve our office, rest in the outdoor use.

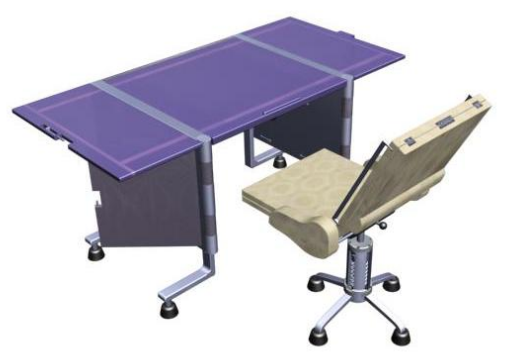

Figure 1. The office desk and chair

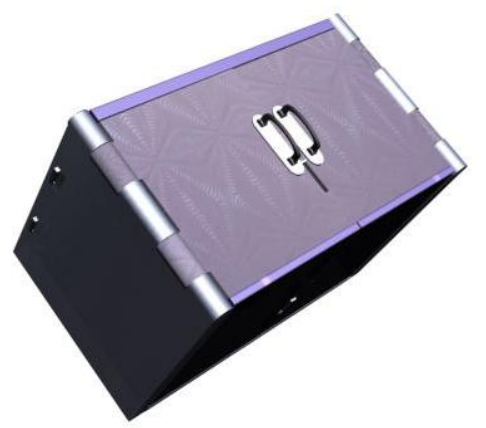

Figure 2. Furniture suitcase

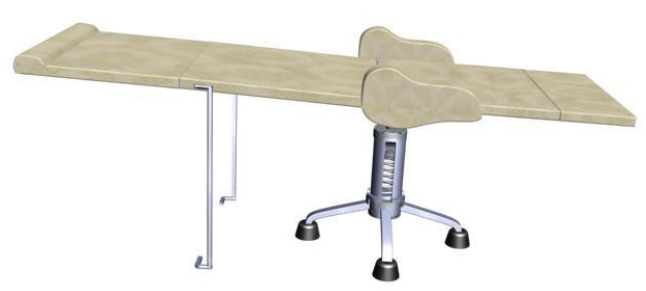

Figure 3. Leisure bed

\section{THE DETERMINATION OF RELEVANT SIZES}

Product design is people-oriented. The relationship between man and machine and environment has been considered in the appearance design of the product. If the desk is designed unreasonably, it can make a person produce fatigue quickly, limb pain, waist and back muscle tension. So this design should not only consider the form of desk, durability, economy, etc., but the body's physiological structure and health problems. As a result, the methods like human body measurement, analysis of the human body structure, physiology, bone movement test and etc were introduced to make the function of the office furniture design from the simple to combined with the feature of human-computer ergonomics principle, make them to accord with human body physiology characteristic direction.[3]

\subsection{Determination of the human body size [4]}

According to GB 10000-10000 the average height of Chinese adults is $164.76 \mathrm{~cm}$. According to our country adult human body structure size in the GB10000-88, the design sizes of the outdoor leisure furniture have been chose following table 1 .

Table 1 . Our country adult human body structure size in the GB10000-88 (unit: mm)

\begin{tabular}{|c|c|}
\hline Sitting height & $855 \sim 908$ \\
\hline Sitting cubits height & $251 \sim 263$ \\
\hline High of the calf and foot & $382 \sim 413$ \\
\hline Sitting width & $403 \sim 457$ \\
\hline Sitting hip width & $321 \sim 344$ \\
\hline Width between two cubits Sitting & $404 \sim 422$ \\
\hline
\end{tabular}

At work, the safe distance is $3 \mathrm{~d}$ to prevent the cracks by extrusion, namely the distance between one leg and the table back is 210 or higher.

\subsection{Determination of the Furniture size}

According to GB10000-88, the sizes of this outdoor leisure furniture were as follows: (unit: $\mathrm{mm}$ )

Desktop board (length $\times$ width $\times$ height) $=720 \times 500 \times 20$

The back of the table (length $\times$ width $\times$ height) $=720 \times 10 \times 435$

Two side of the table (length $\times$ width $\times$ height) $=(500+10) \times 20 \times 435=510 \times 20 \times 435$

The developed surface of the table (length $\times$ width $\times$ height $)=360 \times 10 \times 405$

The whole table (length $\times$ width $\times$ height)

$=(720+40) \times 500 \times 740=760 \times 500 \times 740$

The luggage that the table has been folded (length $\times$ width $\times$ height $)=760 \times 500 \times 435$

The face of the chair (length $\times$ width $\times$ height) $=435 \times 380 \times 25$

The extension of the chair(length $x$ width $\times$ height) $=300 \times 380 \times 25$

The back of the chair (length $\times$ width $\times$ height) $=900 \times 380 \times 25$

The counterclockwise rotation angle of the chair back: $0^{\circ}, 90^{\circ}, 105^{\circ}, 135^{\circ}, 160^{\circ} 180$

The bed surface of the chair unfolded (length $\times$ width $\times$ height $)=1635 \times 380 \times 25$

The chair (length $\times$ width $\times$ height)

$=(450-1635) \times 426 \times(900-410)$

The completely folding chair (length $x$ width $\times$ height) $=700 \times 426 \times 290$ 


\section{MODELING DESIGN OF THE OUTDOOR LEISURE OFFICE DESKS AND CHAIRS}

In this article, the Rhino and 3D Max software have been used the model. [5]

\subsection{Rhino modeling}

Rhino was used to build the digital model entity; the general steps are as follows:

(1) The commands Such as curve and Rectangle were used to establish the framework and the local structure. The chair model was shown in figure 4.

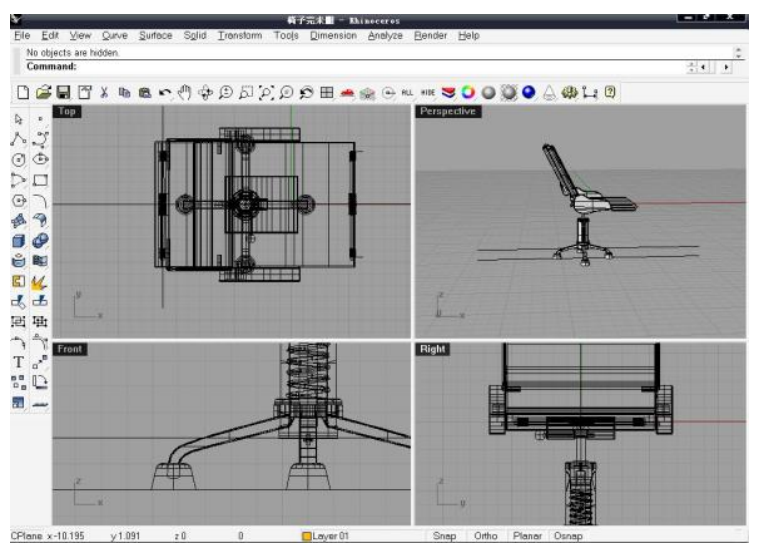

Figure 4. The chair model

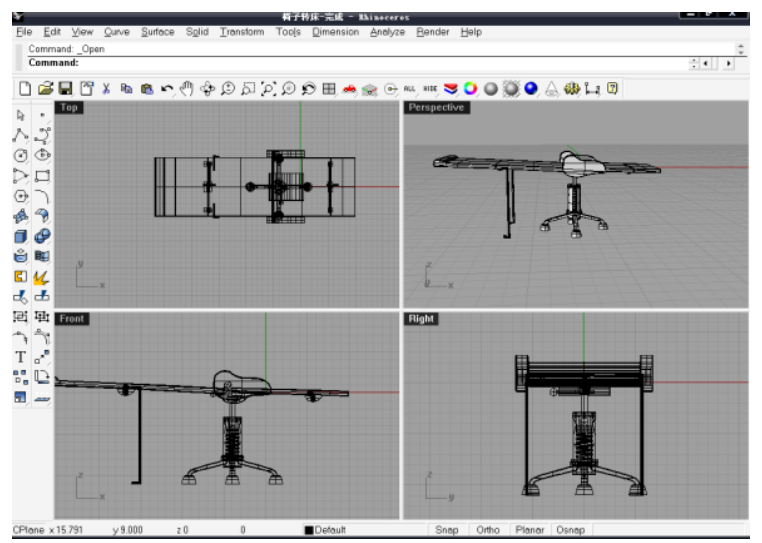

Figure 5. Rotating chair model

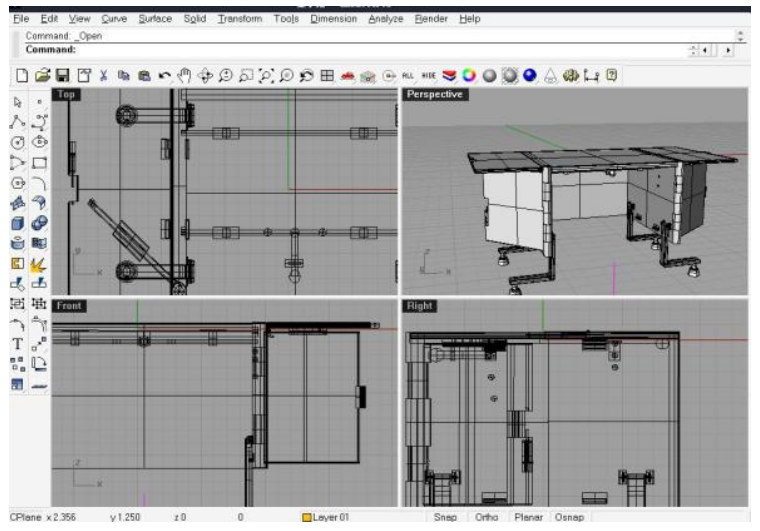

Figure 6. The table model

(2) The commands such as pause, Boolean difference, Boolean union and etc were used to build the overall structure, and chair rotation has been observed at the same time. Rotating chair model was shown in figure 5 .

(3) The commands such as Ellipse, loft, Mirror, trim, the join and etc were used to make table pull ditch, rotating shaft and rotating control connection, etc. The table model was shown in figure 6 .

(4) The commands such as Sweep, Filletsrf, Pause Boolean, Difference and etc were used to build tables and chairs and the relative coordinate relationship as a whole. The model of the table and chair was shown in figure 7.

(5) The commands such as Polyine, circle, Boolean Union and etc were used to make rotation and assembly. The folded combination model of table and chair was shown in figure 8 .

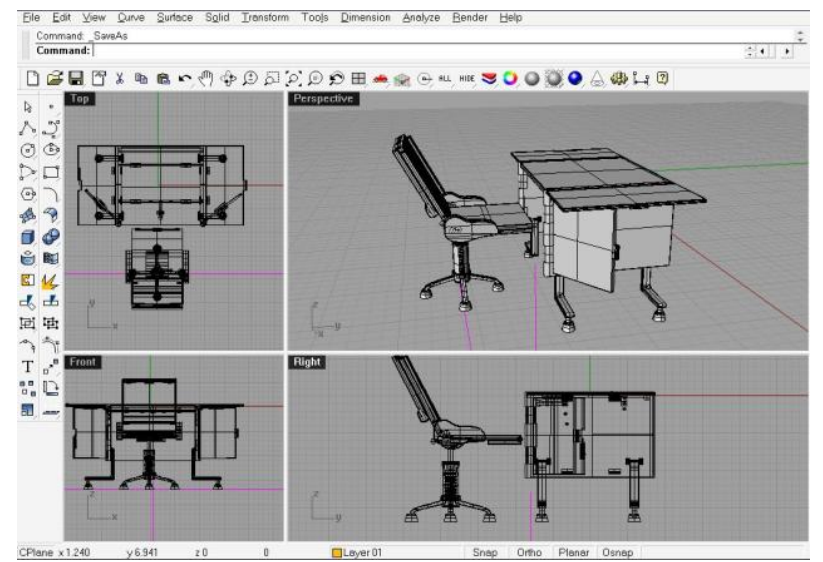

Figure 7. The model of table and chair

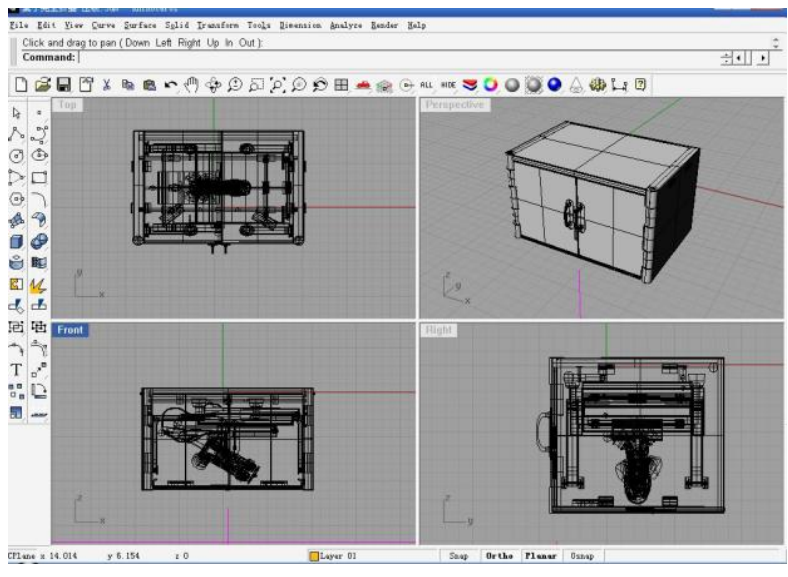

Figure 8 . The folded combination model of table and chair

\section{$4.23 D$ rendering}

The Rhino modeling was exported to the .3Ds format file to import to 3D Max rendering process. The imported file has been sorting and grouping named. Then according to the design requirements, the body has been rendered.

(1) The chair has been rendered and rotated into bed. The chair model rendering was shown in figure 9.

(2) The combination model of the table and chair has been rotated. The combination model of the table and chair was shown in figure 10. 


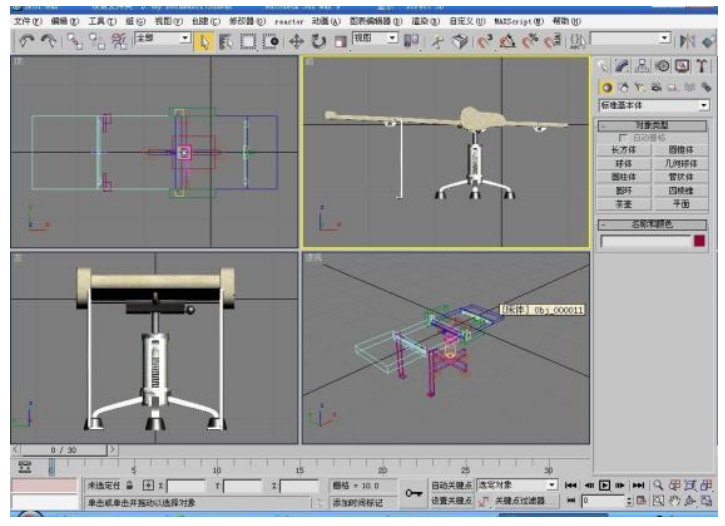

Figure 9. The chair model rendering

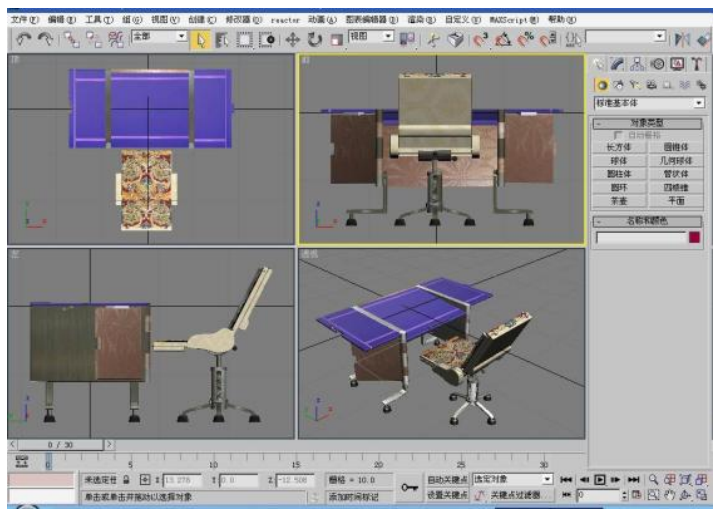

Figure 10. The combination model rendering of the table and chair

\section{CONCLUSION}

The progress of human society depends on the development of the furniture. As the change of society and human life style, the furniture has close relationship with human. In the agricultural society, humans have a third of the time spent on furniture;
In the industrial society, humans have two-thirds of the time spent on furniture; In the knowledge society, humans will have $4 / 5$ of the time spent on furniture. Therefore, the furniture industry has a very broad prospects. So, according to the demand, an indoor and outdoor dual-use multi-function folding leisure office furniture has been designed in the paper. First of all, through a large number of research and decisions, the structure of the product portfolio has been determined. In order to be convenient and quick, the characteristics of the furniture on the market have been collected and analyzed, especially the table, chairs and a bed. According to ergonomics, the parameters of the outdoor leisure office desks and chairs have been determined. The Rhino and 3D softwares have been used to establish the combination of desk and chair to comply with ergonomics, human psychology and aesthetic principles of the product.

\section{REFERENCES}

[1] Deborah Leslie, Suzanne Reimer. Situating design in the Canadian household furniture industry Department of Geography. Canada M5S 3G 1td, 2000

[2] Zhiquan Lao, Jiancai Huang, and etc, 1980. Furniture design atlas. Beijing: Construction of China publishing house.

[3] China agricultural machinery chemical research institute, 1985. Practical mechanical design manual (Part II). Beijing: China agricultural mechanical press.

[4] XiangRuanbao, Xianghua Shao, 2005. Industrial design human-machine engineering. Beijing: Mechanical industry publishing house.

[5] Hao Yuan, 2002. Computer aided industrial design. Beijing: Chemical industry press. 